(A) Bid: Caco-2

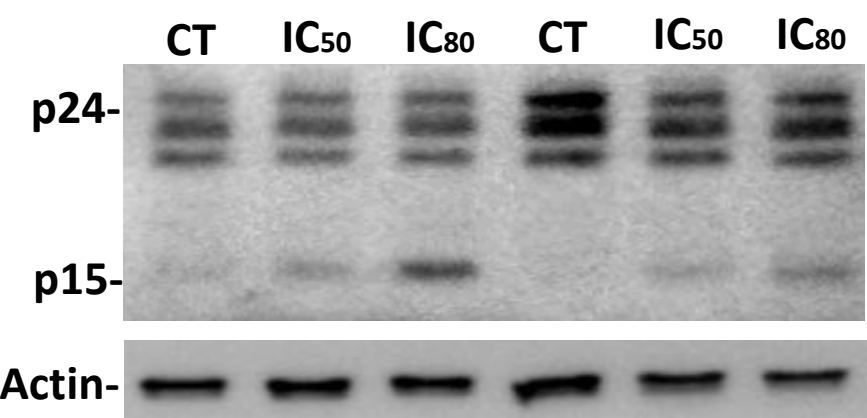

(B) Bax: Caco-2

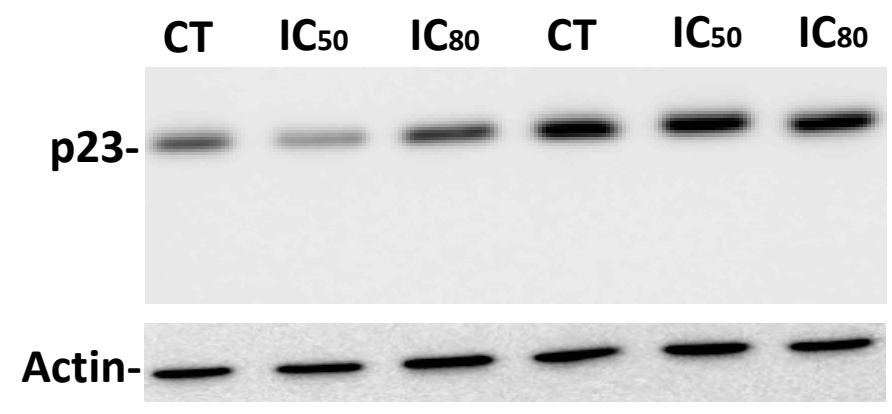

\section{Bid: HT29}

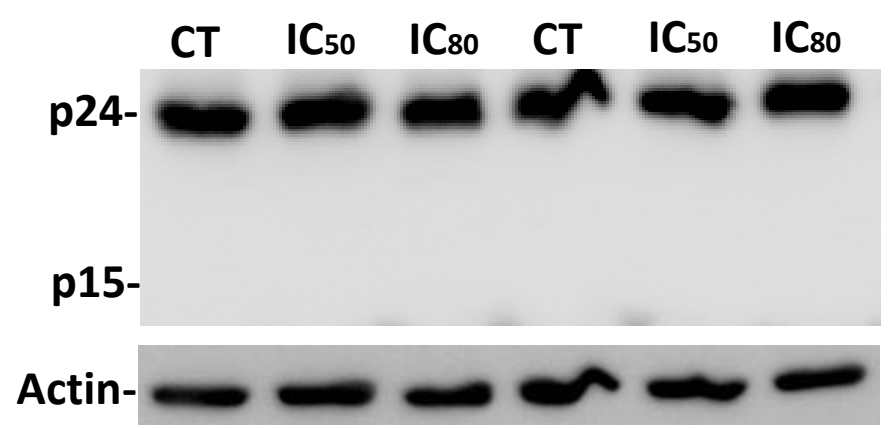

Bax: HT29

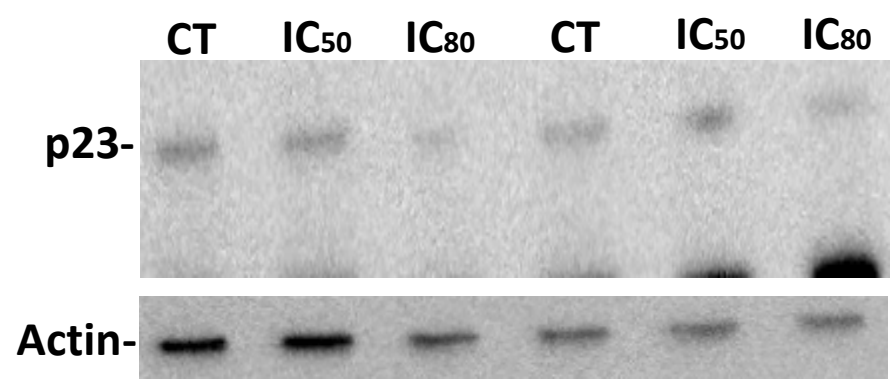

S1 Figure. Supplementary figure 1. (A) Left: Western bloting of the levels of Bid (p24) and t-Bid (p15) in Caco-2 cells. Right: Western bloting of the levels of Bid (p24) in HT29 cells. Note that not levels of t-Bid (p15) were detected in this cell line. Cells were treated with maslinic acid (MA) at $\mathrm{IC}_{50}$ and $I \mathrm{C}_{80}$ concentrations for $4 \mathrm{~h}$. (B) Left: Western bloting of levels of Bax (p23) in Caco-2 cells. Note that not changes in Bax levels were observed in this cell line. Right: Western bloting of levels of Bax (p23) in $\mathrm{HT} 29$ cells. Cells were treated with maslinic acid (MA) at IC ${ }_{50}$ and $\mathrm{IC}_{80}$ concentrations for $4 \mathrm{~h}$. 